Language and Literacy Teachers' Online Professional Development

\title{
Learning Presence and the Reconceptualization of Language and Literacy Teachers' Online Professional Development
}

\author{
Faridah Pawan \\ Rajagopal Sankaranarayanan \\ Rodney Myers \\ Dorcas Miao \\ Indiana University, USA
}

\begin{abstract}
Besides teaching the way they were taught, teachers teach the way they learned (Oleson \& Hora, 2014). Thus, if teachers are to be guided to teach online effectively, their learning experiences and the ways they learn online need to be understood. This study focused on second/foreign language and literacy teachers' (LLTs) Learning Presence (LP) as they engaged online to update their teaching expertise in a formal, doctoral-level professional development program (PD). LP is defined as individuals' self- and co-regulation of their behaviors in online environments in order to be effective learners (Shea et al., 2014). We undertook a mixed-method study involving a content analysis of 9 weeks of online seminar discussions, a 27-question survey that corresponded to Shea et al.'s (2014) LP framework and interviews with the LLTs. The prevalent patterns in the LLTs' online engagement that emerged were in the Strategy Use and Monitoring LP categories. They demonstrated the nature of the engagement amongst LLTs, including peer-to-peer and heterarchical learning. The findings also provided evidence that when supported by the affordances of the online medium, the LLTs' straddled "professionalization and professionalism" goals. In terms of the implications, the findings suggested a reconceptualization of three existing teacher PD models, including that of Darling-Hammond et al.'s (2017). The research's limitations were also identified, pertaining to the way the study was structured, its instruments and their implementation, as well as the constraints of the LP framework itself. Finally, the study concluded with the next steps in research to address the limitations.
\end{abstract}

Keywords: learning presence, language and literacy teachers, online teacher professional development

Pawan, F., Sankaranarayanan, R., Myers, R., \& Miao, D. (2021). Learning presence and the reconceptualization of language and literacy teachers' online professional development. Online Learning, 25(4), 49-73. DOI:10.24059/olj.v25i4.2888 
This study focuses on second/foreign language and literacy teachers' (LLTs) online Learning Presence (LP) (Shea \& Bidjerano, 2010). In the U.S. the online teaching skills and expertise of these teachers are vital to support second language learners of English, also known as English Learners (ELs). At the height of the pandemic, less than half of ELs who had access to online learning programs actually logged in to their online classes (Sugarman \& Lazarin, 2020). As a result, much of the country experienced sharp increases in the percentage of ELs failing to attain grade level achievement, as they learned through the online medium. In a California school district, for example, failures jumped from $34 \%$ to $50 \%$ (U.S. Department of Education, 2021). Given the fact that online schools and instruction are "here to stay" (Singer, 2021) in the post-pandemic era, LLTs' online pedagogical knowledge needs to be closely studied so that they can be supported to serve their online ELs in the most effective way.

One of the most influential sources of teaching knowledge, besides the way they were taught, is the ways teachers themselves learned (Oleson \& Hora, 2014). Thus, this study focuses on an analysis of K-12 teachers' online learning experiences. This research is thus timely in that the recent and sudden immersion of classroom teachers in the online medium left many unprepared. In the U.S., for example, prior to $2020,70 \%$ of teachers and educators did not have any experience teaching online (Hechinger \& Lorin, 2020) and had little prior knowledge to draw upon to inform their teaching. Thus, if teachers are to be guided to teach online effectively, their own online learning experiences need to be understood.

We undertook a mixed method study consisting of a content analysis of discussions supported by survey findings and interviews. In this LP research, we focused on LLTs who were mid-career teacher professionals pursuing advanced doctoral-level education. In our context, the enrollment of teachers in the online doctoral program has increased significantly in the last few years. Between the fall of 2015 and the fall of 2020, we had an enrollment increase of $242 \%$ and this mirrors a national trend of steep enrollment increases in online doctoral programs in general (Vinson, 2020). There is thus a situated need for this study. The main research question for the study is: "What are the LP patterns in LLTs' engagement in an online doctoral-level classroom?"

\section{Literature Review and Theoretical Framing}

In this section, we discuss Learning Presence (LP) as a theoretical concept and review existing research on its various aspects. We also discuss research in the field of Second/Foreign Language Teaching and Learning (SFLTL) that is related to Teaching, Social and Cognitive Presences (TP, SP, \& CP respectively) in Garrison et al.'s (2001) Community of Inquiry (CoI) framework. The reviews in both areas demonstrated that our research fills a gap in an area of research in online SFLTL and contributes to ongoing explorations in LP as a lens for understanding online engagement.

\section{Learning Presence as a Concept in CoI: A Continuing Conversation}

The literature review in this section demonstrates that LP remains an evolving and contested concept. Nevertheless, LP's components in the framework that encompass the concept, address the specific purposes of this research, namely, to understand the ways teachers as learners in the study took charge of their online engagement for learning. 
Shea et al. (2014) defines learning presence (LP) as individuals' self- and co-regulation of their behaviors in online environments to be effective learners. Through research (Shea \& Bidjerano, 2010, 2012; Shea et al., 2014), they converged on the concept and its subsequent framework. Their theoretical perspective is informed by Bandura's (1986) and Zimmerman's (2011) sociocognitive influences (see Table 1). There are three identifiable learner self- and coregulated phases in the framework, namely, forethought (planning, coordinating, and task delegation), performance (monitoring and strategy use), and reflection.

Amidst the ongoing LP research as a concept, its place in CoI remains contested. Through primarily quantitative studies, Shea and his colleagues took the position that learning presence had been left out of the CoI or unnecessarily subsumed under the three other presences (Shea \& Bidjerano, 2012). However, Garrison and Akyol (2013) argued that LP was already inherent and manifested in the intersections of the existing CoI's three presences. In such a community, all participants, including teachers and students alike shared responsibilities to facilitate and direct the co-construction of meaning for themselves and each other.

In response, Shea and his colleagues countered that the three existing presences had generally been approached primarily from the instructors' perspective (see Shea \& Bidjerano, 2010, Shea \& Bidgerano, 2012; Shea et al., 2014). In particular, the focus had previously been on instructors facilitating and setting up of the instructional environment (Teaching Presence); in drawing out authentic projections of themselves as well as that of their students in interactions (Social Presence); and in engaging students through the cyclical stages of triggering, exploration, integration and resolution of ideas (Cognitive Presence). These three presences alone were unable to fully explain student agency, or "the attitudes, abilities, and behaviors that active and engaged students bring to their individual and collaborative online activities" (Shea et al., 2014, p. 10). Furthermore, collapsing LP into the other presences, Shea et al. (2014) asserted, did not reflect the reality of teachers' and students' power dynamics and differentials. Instructors are assumed to be experts, but students are compelled to participate in ways that demonstrated their competency (Shea et al., 2014, p. 11). Teachers design courses and facilitate as well as support students by finding ways to draw students into the center of the learning community. Students, on the other hand, must demonstrate ways in which they are doing so and are attaining instructor-determined performance goals.

Table 1

\section{Learning Presence Categories and Indicators}

\begin{tabular}{ll}
\hline Category & Indicators \\
Forethought and & $\begin{array}{l}\text { Goal Setting: Learner decides upon specific actions and outcomes. } \\
\text { Planning: Learner decides on methods or strategies appropriate for the task. } \\
\text { Coordinating Tasks: Learner distributes and sequences sub-tasks to other/self for future } \\
\text { completion. }\end{array}$ \\
\hline Monitoring & $\begin{array}{l}\text { Checking for Understanding: Learner seeks verification of understanding of task, events, } \\
\text { or processes. } \\
\text { Identifying Problems: Learner identifies difficulties or problems that interfere with }\end{array}$
\end{tabular}

Identifying Problems: Learner identifies difficulties or problems that interfere with completion of tasks, performances, products, or other outcomes.

Noting Completion: Learner makes comments that indicate that certain tasks or activities have been finished to support attaining a goal.

Evaluating Quality: Learner evaluates the quality of a product, its content, or its parts as working toward completion.

Taking Corrective Action: Learner makes statements that monitor individual or group performance that results in corrective action based on feedback or reflection. 
Appraising Engagement: Learner comments about self or others' engagement, interest, commitment, or participation (includes personal "reactions" to tasks, materials, and activities).

Recognizing Learning Behaviors: Learner makes statements about individual or group preferences, strengths, or weaknesses as learners.

Advocating Effort: Learner encourages others to contribute or focus on interest, commitment, or participation (includes personal "reactions" to tasks, materials, and activities).

Noting Use of Strategies: Learner makes statements that illustrate that they are mindful and aware of the strategies that they are using.

Strategy Use Seeking or Offering Help: Learner requests, offers or provides assistance related to learning materials, tasks, processes, or products.

Recognizing Knowledge Gap: Learner makes statements indicating that they are aware of a gap in knowledge and its connection to the current task, process, or product.

Reviewing: Learner makes comments noting the need to review or to complete reviewing content related to the course.

Noting Outcomes: Learner makes statements in which they acknowledge the relevance of current tasks or processes to a future outcome.

Seeking and Offering Information: Learner looks beyond course content and materials to locate additional information to deepen understanding.

Reflection Change in Thinking: Learner makes statements that indicate a change in thinking as a result of a process, product, or outcome.

Causal Attribution: Learner makes statements in which they credit their results to their performance (i.e., use of forethought, planning, monitoring, strategies).

Note. The chart is adapted from Shea, P., Hayes, S., Uzuner-Smith, S., Gozza-Cohen, M., Vickers, J. and Bidjerano, T. (2014). Reconceptualizing the community of inquiry framework: An exploratory analysis, Internet and Higher Education, 23, 15-16. https://doi.org/10.1016/j.iheduc.2014.05.002. We abbreviated the original chart by juxtaposing the indicators and their descriptions. We also did not include example quotes and sources that were provided in the original chart.

Existing research involving LP demonstrates that there are continuing efforts to refine and formulate Shea et al.'s (2014) articulation of the LP's conceptual framework. One set of research focused on refining LP's components as a learning construct. For example, in a study of 180 U.S. undergraduate students, Cho et al. (2017) argued that self-regulated learning (SRL) was a critical component in LP because it was the primary factor that influenced the students' sense of achievement and confidence. Their findings resonated with that of Pool \& Reitsma's (2017) findings that SRL skills such as time management, coordination, and management of tasks were critical LP components of 58 South African teacher-trainees. In Kang et al.'s (2014) study, LP as a construct, consisted of Cognitive, Emotional, and Social Presences. Using these LP components, they demonstrated that each could predict different outcomes, namely improvement, satisfaction, and achievement outcomes, respectively.

There was also research undertaken that strove to show LP's impact on learning that correlated with the original CoI presences. For example, using a Chinese CoI version that included LP, Ma et al. (2017) surveyed 350 Chinese undergraduate students and concluded that a correlation was evident between increased students' perceptions of LP and higher levels of TP, SP, and CP. In a qualitative study, Scott et al. (2016) researched students in informal learning virtual spaces, in a Master's program. The cognitive benefits of LP correlated with that of CP's. In their survey of 696 online 8th to 12th grade students, Zhang and Lin (2021) provided 
empirical evidence that the cumulative effects of the Teaching (TP), Cognitive (CP), and Learning (LP) Presences led to higher course satisfaction and course grades.

A third line of research focused on the unique insight LP was able to yield about learning and learners that eluded the three existing Presences. Popescu and Badea (2020) explored LP along with the Presences in a blended learning environment through a content analysis of students' blog posts and tweets. The researchers found that the use of LP enabled them to identify students' self- and co-regulatory behaviors, barely reflected by the other Presences. Blaine's (2019) research demonstrated that there were opposing differences between teachers' and students' perceptions of the success of a high school's Virtual Advanced Placement courses. The student views could only be captured when LP was used in the qualitative content analysis in conjunction with CoI. Witthaus (2018) utilized LP in her analysis of the MOOC experiences of 10 refugees in Germany. Only with LP, was she able to identify these individuals' goal setting and planning strategies for their learning, amidst the chaotic uncertainty of their circumstances.

Although, LP's place in CoI remains unresolved and LP as a concept is still the subject of active investigation, the mixed-method research reported here served to add another layer to the ongoing conversation. It did so by looking into LP's utility as a lens to bring to light the online learning patterns of teachers as learners. This learner perspective could provide insights into students' efforts to take charge of their own learning that could complement their instructors' efforts to improve online teaching and learning.

\section{CoI and Online Presences in Second/Foreign Teaching and Learning (SFLTL)}

Garrison, Anderson, and Archer's (2001) CoI framework has been the guiding framework in online learning and teaching research SFLTL. Social (SP), Cognitive (CP) and Teaching (TP) Presences are fundamental in research in the area. However, our survey of research revealed that that LP in SFLTL is largely unexplored. Thus, the current research attempts to fill the gap in LP research in the area.

A review of current research (2015-2020) in SFLTL from research journals, conference proceedings, and dissertations identifies several observable trends in the study of online presences. One trend is the identification of CoI's existing Presences in online language learning experiences (see Toyoda, 2015; Sarieva \& Badrinathan, 2016; Tunceren, 2017; Nami et al., 2018; Omohundro, 2019; and Gunter et al., 2019). For example, Toyoda (2015) explored CP in a Japanese-as-a-foreign language course in which Australian students developed, shared, and discussed their videos through YouTube and Facebook with peers in Japan to increase intercultural awareness. Discussions between the two groups demonstrated higher order thinking - reflection, synthesis, and analysis - that was further facilitated by TP and SP.

The second line of inquiry is on the roles and impact of those Presences. In particular, research has focused on how those presences contributed to effective online language teaching and learning that led to successful performances (see, for example, Batardière, 2015; Konstantinidis \& Goria, 2016; Rodriguez, 2016; Ozbek et al., 2017; Rubio et al., 2018; Schumann, 2019). For example, Ozbek et al.'s (2017), demonstrated that English teachers' TP in a Turkish university's English class undertaken in Second Life, an online virtual world, positively affected communicative engagement amongst English-as-a-Foreign language (EFL) students. The TP involved a range of scaffolding pre-activities, including role-playing scenario designs and translation checks. All served to increase authenticity and just-in-time support to enhance language use (instead of language knowledge) that is primary in language acquisition.

The implementation of tools and interventions to enact the Presences in language teaching has also been a subject of investigation (see, for example, Shin, 2016; Sun et al., 2017; 
Elverici \& Karadeniz, 2018; Fornara \& Lomicka, 2019). Of particular interest to researchers has been the use of social media tools and instructional approaches in establishing SP to enhance community building in the classroom. For example, Fornara and Limicka (2019) researched French and Italian teachers' use of Instagram by U.S. undergraduate students studying the languages. They found that in using the application, students posted a high density of visual "self-disclosure" activity posts, an SP community building indicator. Such public sharing of posts raised curiosity that drew the classroom community together in actively seeking language practice beyond the classroom.

Finally, Kurek and Müller-Hartmann's (2019) is the only research that we uncovered thus far in SFTL to include LP. It was an action research of 38 Polish and German students training to be Teachers of English to Speakers of Other Languages (TESOL). The research demonstrated that LP worked in tandem with TP to counterbalance tensions and challenges in the ways the international team of teachers in a virtual classroom worked together. This was achieved by engaging the teacher trainees in the preparatory design task phase, where they were given the opportunity to take charge of designing rules of conduct and problem-solving.

The review above of CoI-related SFLTL research in the virtual environment demonstrated that, except for LP, the existing presences (TP, SP, and CP), prevailed in the area. The research reported in this manuscript thus undertook an inquiry to address the absence of studies in LP. There is also both a need and value in our immediate context to studying LLTs in SFLTL who are doctoral students. As mentioned earlier, in our program, enrollment of teachers in doctoral programs has increased dramatically the last five years. Most of these doctoral students are part-time students who are fully employed. This is not surprising; the online medium has provided a means for professionals such as these students to maintain their jobs while pursuing their tertiary goals, and thus the reason for their predominance nationally in higher education programs in the medium (Bamforth, 2021).

The literature review above provides the justification for our research. We undertook the research because, as demonstrated above, we wanted to explore the ability of LP, as defined by Shea et al (2014), to trace the patterns of learners' engagement from a relatively new lens. Also, this research is timely because LP is an under-researched area in SFLTL and is needed in our context. Our research question thus centered on the LP patterns of language and literacy teachers' (LLTs) engagement in an online doctoral-level classroom.

\section{Method}

We undertook a mixed-method study consisting of a content analysis of discussions supported by descriptive statistics from a survey. The study also included individual interviews with highly engaged students. Thus, to identify LP patterns and instances, we undertook a content analysis (Woods et al., 2002) of discussions in an LLTs' online classroom using Shea et al.'s (2014) LP framework. We then triangulated our findings in two ways. First, to situate them in a larger context, we developed and sent out a survey to all LLTs in an online doctoral program (see Appendix A). Finally, to gain deeper insight and to contextualize the findings in the reasons behind the LP patterns, we interviewed the LLTs in the online classroom.

\section{Research Context}

The research was conducted in a 16-week online seminar that took place in the 20192020 academic year. The seminar explored the intersections of theory, research, and practice in second/foreign language and literacy. The participants were 17 second/foreign language teaching 
and literacy professionals who were pursuing the online doctorate. The LLTs ranged in age from the mid-thirties to their late fifties, with two-thirds of the students being females, which is a norm for this particular online doctoral program as a whole. All were fully employed as language/literacy teachers and/or teacher educators (LLTs). Thus, the LLTs were pursuing their education while continuing in their jobs.

In the online class, although the instructor developed a syllabus and a readings list, the LLTs had the option of selecting readings provided for discussions or using readings they selected from elsewhere. The instructor and the LLTs also took turns posting questions and/or discussion prompts for discussions.

Figure 1

Class discussion routine

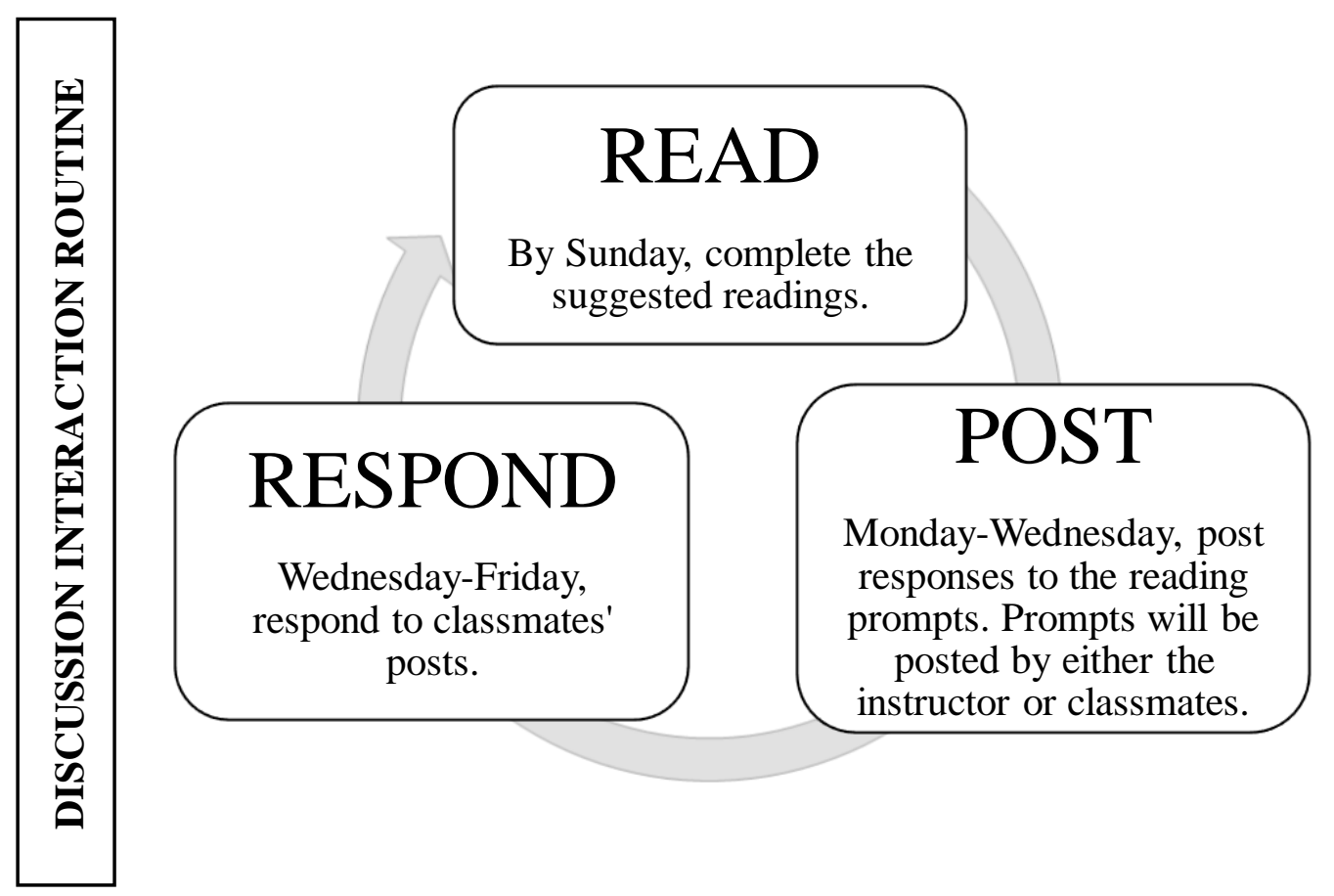

\section{Data Collection and Analysis}

Data were collected from three sources. The first source of data consisted of 9 weeks of class discussions (1,614 speech segments, 720 postings, 145,810 words). The second source was responses from a survey sent out to all LLTs in the online program, consisting of 27 questions based on Shea et al.'s (2014) LP categories and indicators (see Appendix A). The response return rate was 47.2\% (34 of 72). Finally, for a deeper analysis and to uncover reasons for the LP patterns utilized, we focused on the (volunteer) interview responses ( 40 minutes each) of three of 
the most engaged individuals, identified from the course analytics that showed them to lead in the number of messages they sent out and the responses they received from classmates.

To uncover instances of LP patterns as per Shea et al.'s (2014) categories and indicators, we focused on data collected from the LLTs' discussions. We chose to look at 9 weeks where discussions were the core of the class and excluded the early weeks that consisted of them figuring out class logistics and the weeks that they were working on individual assignments. Six coders initially worked in pairs before all of them came together to compare their coding. Before the coding, they spent eight weeks discussing and familiarizing themselves with Shea et al.'s (2014) framework. The coders were also trained to use speech segments as a unit of analysis. Henri and Rigault (1996) defined a speech segment as "the smallest unit of delivery linked to a single theme, directed at the same addressee (all, individual, subgroup), identified by a single type (illocutionary act), having a single function (focus)" (p. 62). An example is provided below: Edward, [i.e., targeted at an individual]

This resonated with me as the idea of the teaching-learning transaction [i.e. the overall theme]. It really is two sides of the same coin. Also, that instead of focusing on teaching that we focus on LEARNING. If we learn how to coach learners instead of how to "teach" a person [i.e. focus within the theme], I think we will overall be more successful [i.e. the illocutionary act of intent]. (Naomi, First Quarter, 2019-2020 Academic Year)

The coders then undertook a content analysis of individual discussions, using Shea et al.'s framework to describe LP patterns, as per the focus of this study. They then met to compare their work and to discuss any disagreements. The cumulative interrater agreement across the three groups was at $83.3 \%$, determined by the number of agreements over total agreements and disagreements (Bauer, 2000).

To situate the LP findings from the class discussions within the opinions of the larger group, we developed an online survey, using Shea et al.'s (2014) indicators (see Table 3). The survey was sent to all LLTs in the online program at the time. The survey consisted of 27 questions that corresponded to each learning indicator as per the protocol by Shea et al. (2014). We used the Likert Scale consisting of Always, Often, Sometimes, Seldom, and Never (see Appendix A). The information provided a triangulating insight into the ways the LP patterns displayed in classroom discussions reflected or did not reflect the engagement patterns reported by LLTs in the program.

To uncover the reasons for the LP presence, we undertook 40-minute individual interviews with 12 students who made themselves available to do so. However, we focused on the responses from three of the most highly engaged students. We identified the reasons provided by the students, question by question (see Appendix B for questions).

\section{Findings}

The findings from the three sources of data triangulated the information we sought to answer the study's research question on LP patterns. Thus, below we report the findings from the content analysis, the survey, and the interviews.

\section{Content Analysis Findings}

Using Shea et al. (2014) framework (see Table 1), the content analysis enabled us to trace LP patterns in the classroom discussions. From the discussion segment of the class, 1,326 out of 
1,614 segments $(82.2 \%)$ were coded using the framework. In descending order, the coding demonstrated LP categories in the following manner: Strategy Use (605); Monitoring (566); Forethought and Planning (100); and Reflection (55).

Table 2

Classroom-Based Content Analysis Findings

\begin{tabular}{|c|c|c|c|c|c|}
\hline \multirow[t]{2}{*}{ Categories } & Indicators & $\begin{array}{c}\text { Indicator } \\
\text { Total }\end{array}$ & $\%$ & $\begin{array}{c}\text { Category } \\
\text { Total }\end{array}$ & $\%$ \\
\hline & Goal setting & 35 & 2.64 & & \\
\hline Forethought \& & Planning & 53 & 4.00 & 100 & $7.54 \%$ \\
\hline \multirow[t]{5}{*}{ Planning } & Coordinating tasks & 12 & 0.90 & & \\
\hline & Checking for understanding & 31 & 2.34 & & \\
\hline & Identifying problems & 56 & 4.22 & & \\
\hline & Noting completion of tasks & 8 & 0.60 & & \\
\hline & Evaluating quality & 88 & 6.64 & & \\
\hline \multirow[t]{7}{*}{ Monitoring } & Taking corrective action & 13 & 0.99 & 566 & $42.68 \%$ \\
\hline & Appraising engagement & 272 & 20.51 & & \\
\hline & Recognizing learning behaviors & 12 & 0.90 & & \\
\hline & Advocating effort & 69 & 5.20 & & \\
\hline & Noting the use of strategies & 17 & 1.28 & & \\
\hline & Seeking or offering help & 60 & 4.53 & & \\
\hline & Recognizing knowledge gap & 60 & 4.53 & & \\
\hline \multirow[t]{3}{*}{ Strategy Use } & Reviewing & 8 & 0.60 & 605 & $45.63 \%$ \\
\hline & Noting outcome expectations & 14 & 1.05 & & \\
\hline & Seeking/ offering information & 463 & 34.92 & & \\
\hline \multirow{2}{*}{ Reflection } & Change in thinking & 46 & 3.47 & 55 & $4.15 \%$ \\
\hline & Causal attribution & 9 & 0.68 & & \\
\hline
\end{tabular}

In Strategy Use, LLTs focused predominantly on "Seeking/Offering Information" (463 segments). This indicator is defined by learners going beyond classroom materials for more information to deepen understanding. Edward's quote below is illustrative in that he was offering information on materials that he had read elsewhere:

I feel that the work of psychology researchers and others in the field are necessary to complete the picture and do a much better job explaining such non-cognitive factors and how it relates to student language learning. (Edward, First Quarter, 2019-2020 Academic Year)

Monitoring was the next category coded most frequently, particularly pertaining to the indicator of "Appraising Engagement" (272 segments) whereby the LLTs commented or expressed reactions to their own or that of their classmates' input and participation. Yvette's quote below demonstrated that she appraised and assessed her classmate's contribution in terms of its value: 
I now see value in approaching power and privilege through your way of combining a critical cosmopolitan theoretical framework with critical literacy pedagogical practices.

Where U.S. students have opportunities to view, consider, unpack, and critique the experiences of students in countries outside the U.S. they will be more likely to engage in higher levels of empathy and 'conscientization'... (Yvette, Second Quarter, 2019-2020, Academic Year)

Within the category of Forethought and Planning, the "Planning" (53 segments) indicator is exemplified by the following quote that demonstrates that "observation" was the planned action:

I am trying to make connections between ZPD and a learner's motivations for learning a language. How much of language learning motivations are fully taken into account in Lantolf et al's position, is what I am trying to observe through this week's readings. (Rose, Second Quarter, 2019-2020 Academic Year)

Shea et al.'s Reflections category and its indicators were also coded in the discussions portion of the class with 55 segments. Of these, 46 segments were coded for "Change in Thinking" and the rest for "Causal Attribution" (9 segments). In the following quote, the LLT could be seen attributing the discussions with peers and his own efforts to his increased understanding:

I had an "aha" moment after reading and discussing about narratives this week... On top of that, going through 12 years of photos for the multimodality aspect deepened my reflection, and ultimately, my understanding of the multi-literacies experience. (Cormac, Second Quarter, 20192020 Academic Year)

The content analysis of classroom discussions demonstrated that although all categories were reflected in the LLTs' discussions, Strategy Use (605 segments) and Monitoring (566 segments) were the categories defining their LP patterns. They constituted $88.31 \%$ of the learning engagement.

\section{Survey Findings}

To situate findings in a larger context, we administered a survey to the LLTs in the online program at the time of the study. We focused on responses in the "Often" column, where the highest responses were found. We considered, thus, the responses in this column to be the most representative of the surveyed students' opinions as a whole.

Table 3

Survey Responses of Students in the Online Doctoral Program

\begin{tabular}{llcc}
\hline Categories & Indicators & $\begin{array}{c}\text { Participants } \\
\text { Reporting } \\
\text { "Often" }\end{array}$ & $\begin{array}{c}\text { Percentage of } \\
\text { Respondents }\end{array}$ \\
\hline Forethought \& Planning & FOR-Goal setting & 7 & $20.59 \%$ \\
(FOR) & FOR-Planning & 7 & $20.59 \%$ \\
& FOR-Coordinating tasks & 6 & $17.65 \%$ \\
Monitoring (MON) & All FOR Indicators & $\mathbf{2 0}$ & $\mathbf{1 9 . 6 1 \%}$ \\
& Checking for understanding & 16 & $47.06 \%$ \\
& Identifying problems & 15 & $44.12 \%$ \\
& Noting completion of tasks & 5 & $14.71 \%$
\end{tabular}




\begin{tabular}{llcc} 
& Evaluating quality & 16 & $47.06 \%$ \\
& Taking corrective action & 12 & $35.29 \%$ \\
& Appraising engagement & 12 & $35.29 \%$ \\
& Recognizing learning behaviors & 12 & $35.29 \%$ \\
& Advocating effort & 10 & $29.41 \%$ \\
& Noting the use of strategies & 13 & $38.24 \%$ \\
Strategy Use (SU) & All MON Indicators & $\mathbf{1 1 1}$ & $\mathbf{3 6 . 2 7 \%}$ \\
& Seeking or offering help & 7 & $20.59 \%$ \\
& Recognizing knowledge gap & 16 & $47.06 \%$ \\
& Reviewing & 13 & $38.24 \%$ \\
& Noting outcome expectations & 19 & $55.88 \%$ \\
Reflection (RF) & Seeking/ offering information & 14 & $41.18 \%$ \\
& All SU Indicators & $\mathbf{6 9}$ & $\mathbf{4 0 . 5 9 \%}$ \\
& Change in thinking & 8 & $3.85 \%$ \\
\hline & All RF Indicators & $\mathbf{8}$ & $\mathbf{3 . 8 5 \%}$ \\
\hline
\end{tabular}

Similar to the classroom-based findings, Monitoring and Strategy Use ranked high in the "Often" column of the survey. The findings, however, showcased that different indicators were ranked differently in the survey and classroom-based findings (see Table 5). For example, under the Strategy Use category, in the survey and under the "Often" column, "Noting Outcomes" and "Recognizing Knowledge Gaps" ranked highest, whereas "Seeking or Offering Information" and "Seeking or Offering Help" were most frequently identified in the content analysis in the classroom-based findings. Under the category of Monitoring, "Checking for Understanding" was ranked first in the survey, while that was the case for "Appraising Engagement" in classroom discussions.

Table 4 Comparison of Most Frequent Survey Responses and Coding of Classroom-Based Discussions

\begin{tabular}{llll}
\hline LP Categories & Program Survey & Classroom discussions \\
\hline Strategy Use & 1. & Noting Outcomes & 1. Seeking or Offering Information \\
Monitoring & 2. Recognizing Knowledge Gaps & 2. Seeking or Offering Help \\
& 1. Checking for Understanding & 1. Appraising Engagement \\
Forethought \& Planning & 2. Evaluating Quality & 2. Evaluating the Quality \\
& 1. Planning & 1. Goal Setting \\
Reflection & 2. Goal Setting & 2. Planning \\
\hline
\end{tabular}

\section{Interview Findings}

We report here the responses from the three students (see Appendix B for interview questions). Questions 1 and 2 asked students to indicate why their LP primarily consisted of seeking/providing information and monitoring/appraising their own and that of others' participation. In response to Question 1, the LTTs interviewed indicated that seeking and offering information were the ways they learned as expressed by Valerie (September 2020) who had the following to say:

This is the way we learn... We are all together...my classmates, my professor, and the fishbowl guests we all join in. I am reading and responding to their stuff and vice versa. 
On his part, Donovan pointed out this way of learning was of mutual benefit to him and his classmates:

When I contribute, I also learn. I make connections I did not make before and come up with something new. (August 2020)

In response to question 2 regarding their pattern of appraising engagement, the following LLTs' responses indicated two reasons, namely, to check for connections to their area of study and the other, the connections to their work.

In the class, the information is always available. I am looking to find information that contextualizes my understanding of the concepts... By following discussions, I am collecting theories I can use for my research. (Edward, August 2020)

Donovan, on his part, had the following to say:

I look for ways that others can help me to draw out my understanding of the things we talked about. (August 2020)

The quotes below, on their part, reflect that the LLTs were looking for ideas to inform their practice:

Because we are in our settings... are from everywhere, Egypt, Afghanistan, Japan, Korea, and Alabama ...no matter...we can test our ideas immediately in our own classrooms.

(Donovan, August 2020)

Valerie's quote below shows that she was using the discussions to go beyond her practice and to find ways to continue to serve in her immediate environs:

I am getting help from others for teaching ideas. Everybody in the class has been there like me. The discussions help me move beyond my "practice shell" ...Teachers are socioprofessionals as you said...we look for ways to be able to connect and give back to our community. (Valerie, September 2020)

\section{Discussions and Implications}

In this section, we discuss the significance of the findings and their implications to teacher professional development in the online environment. The significance relates to the findings' demonstration of the ways the affordances in the online medium reinforced studentdriven "epistemic engagement." The affordances also enabled the juxtaposition of "professionalization and professionalism." In terms of the implications, the findings suggested a reconceptualization of existing teacher professional development (PD) models.

The prominence of the Strategy Use category, specifically its "Seeking/Offering Information" indicator in both the classroom discussion and the survey, demonstrated the nature of the students" online engagement at the doctoral level. The "Seeking and Offering Information" 
indicators helped to showcase specifically how the LLTs sustained the socio-constructivist group knowledge building or "epistemic engagement" as defined by Larreamendy-Joerns and Leinhardt (cited in Shea \& Bidjerano, 2010, p. 1722). In that sense peer-to-peer learning defined engagement at this advanced level and involved doctoral students relying on each other as "learning partners" (Flores-Scott \& Nerad, 2012, p. 74) in a horizontal heterarchical process (Hedlund, 1986) of peer apprenticeship based on reciprocity. As Donovan indicated in the August 2020 interview, it was through that approach that he enacted his LP; when he contributed to others, he learned in return.

The online medium served to reinforce this type of student-driven engagement as it enabled the LLTs themselves to witness learning unfolding in a deliberative, and "public way" (Smith \& MacGregor, 1992, p. 11) as they worked together. This transparency, afforded by the medium, engaged LLTs in a collaboration that enabled them to follow, contribute to and support each other as they moved toward the same goal of uncovering, making sense of, validating, transforming, and creating knowledge. Also, the prevalence of LP patterns in the findings on "Seeking/Offering information," resonated with research on the value professionals place in using the online medium to update their knowledge. For example, Milligan et al.'s (2014) research demonstrated that the medium is useful when it can facilitate the " $4 \mathrm{C}$ " stages that take professionals beyond merely consuming pre-structured information to a collaborative stage where they can partake in connecting, creating, and contributing to the learning of others.

The prominence of the Monitoring LP category in the classroom discussion and the survey findings reflects the reality that the online medium enabled the LLTs to straddle professionalization and professionalism goals. Crandall (1993) defined the former as experiences over a specified amount of time, at the end of which, individuals are formally credentialed, such as receiving an EdD in the case of this study's LLTs. The latter, professionalism, refers to the process of life-long learning that individuals engage in to sustain and improve their expertise to serve needs in their context, for as long as they are in their profession. As online doctoral students, the LLTs' LP enactment reflected them processing information for their own individual purposes of obtaining the doctorate (i.e., their professionalization goal). On the other hand, as teachers, they were also engaged in connecting their classroom learning to their local practice in order to remain relevant and to be able to serve their immediate teaching population well (i.e., their professionalism goal). Pursuing their online education, thus enabled them to undertake both goals simultaneously. For example, in terms of the professionalization goals, Edward's response quoted earlier (Edward, August, 2020), suggested that the monitoring helped to connect the "theory dots." Professionalism as a goal was evident in Donovan's quote from August 2020, in that the monitoring was a means for him and his classmates to immediately test ideas in their own classrooms.

We further reflected on how the research findings helped us to modify existing professional development (PD) models. We specifically referred to three models demonstrated in three concentric circles in Figure 2. The central circle consists of features in Darling-Hammond et al.'s (2017) effective PD model; the second ring contains those in Richardson and Diaz Maggioli's (2018) model for English language teachers (ELTs) specifically. Finally, the third ring is the Mokko and Pawan's (2021) model that emerged from their two-year research on the informal PD of the TESOL who identified PD features that led them to consistently pursue informal learning by means of online Personal Learning Networks. Although our research using Shea et al.'s LP framework, did not lead to a comprehensive reconceptualization of the models, 
its place in them was evident. Additionally, the framework enabled us also to refine our thinking about specific PD features in the models and those to include in future formal online PDs.

The Strategic Use LP category, and in particular, the "Seeking/Offering Information" reiterated that peer-to-peer collaboration was an important component, because it was present across the three models. The indicator made transparent the heterarchical nature of the collaboration in terms of how the LLTs in this research took turns as temporary "more knowledgeable others" (MKO) (Johnson, 2006) in jointly making sense and processing ideas. In that regard, findings in the current study suggested a move beyond Darling-Hammond et al.'s (2017) assertion that effective PDs should have the standard feature of being "expert-coached and supported." The findings suggested that it was more important that the experience was mediated regardless of who undertook the mediation.

Similarly, the prevalence of the indicator in the research suggested refinements to the feature of “Active Learning” in Darling-Hammond et al.'s (2017) in which hands-on experiences were prioritized. Milligan et al.'s (2014) 4C stages resonated in the current study's findings as well in the Mokko and Pawan's (2021) study. The Connection and Contribution stages could be seen as prominent in statements such as that by Naomi, one of the LLTs, in which she said, "sharing is learning" (personal communication, July, 2020). Online formal PD programs at this level, thus, should prioritize similar types of engagement.

On its part, the Monitoring LP category, and in particular, "Appraising Engagement," findings in the study, demonstrated that the LLTs searched for and were attuned to the connections between their work in class (professionalization goal) and to their local practice (professionalism goal). Rather than the content-focused component in Darling-Hammond et al.'s model, those monitoring connections were one of the key components of their learning. (In the Mokko and Pawan's (2021) study, an experienced teacher exclaimed that finding the connections made him feel "smarter" after 30 years of teaching). In this sense, there was a heightened awareness on the LLTs' part regarding monitoring their own and that of their classmates' actions toward the achievement of the two goals. Thus, this awareness added the new component of connections to the discipline, to the local situatedness feature that was identified in Richard and Diaz Maggioli’s (2018) and in that of Mokko and Pawan's (2021) model.

Such awareness is defined by Candy (2019) and Ponton and Rhea (2006), as autonomy that complements self-directed learning. In this regard, it connects directly to the LP category of Forethought and Planning in which learners enacted their LP in setting goals for themselves and in planning their next steps. The findings suggested "autonomy" as a necessary addition to the Mokko and Pawan's (2021) self-directed learning feature. Autonomy also further refined a PD feature in Richardson and Diaz Maggioli's (2018) model that focused on the need for PD developers to specifically target teachers' expressed needs. The current study's findings suggest that the developers should instead enable teachers to enact their autonomy rather than taking charge of addressing the needs. The LP indicators in Shea et al.'s (2014) Forethought and Planning category can serve as guides for helping teachers decide on specific actions and outcomes, strategies, and methods to achieve them, and in helping them to coordinate the tasks needed in their online PD experiences.

Finally, similar to the existing three models, the LP category of Reflection was also evident in the data and thus important as a component in formal online PDs. The reflections pertained to indicators of "Change and Thinking" and "Causal Attribution." In conclusion, Shea et al.'s (2014) LP framework enabled us to trace the patterns of learning amongst our teachers 
and the reasons for them. With that information, we hope to serve our teachers and doctoral students in ways that complement the LP they find important to maintain in their formal online classroom. In the meantime, we are encouraged by Naomi's (July, 2020) comment and enthusiasm for learning in the medium:

I love being an online grad student. If I could be paid to do so, I would make it my career.

Figure 2

The place of LP in the reconceptualization of formal online teacher professional development 


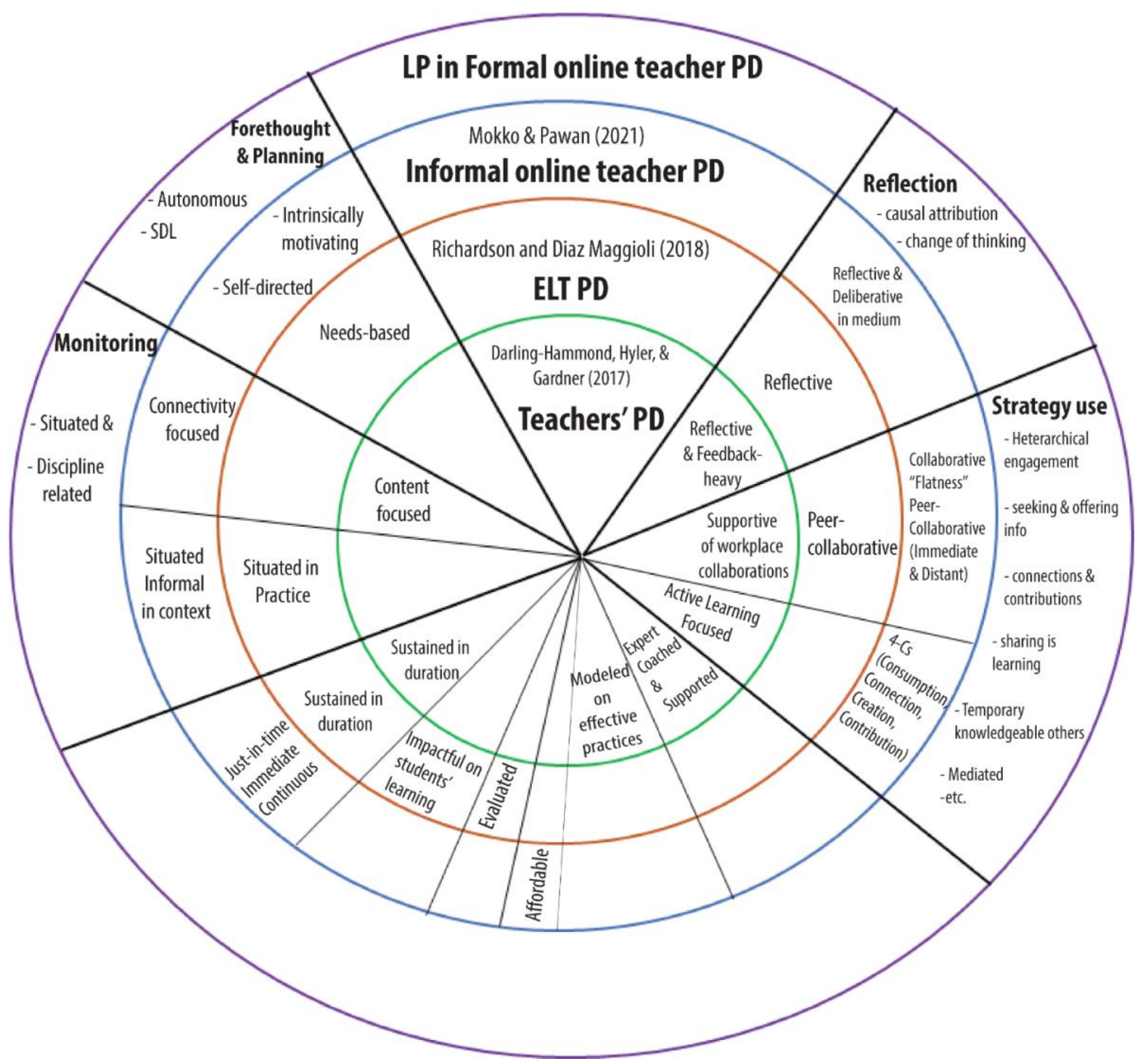

\section{Limitations and Suggested Next Steps}

In this section, we discuss the research's limitations pertaining to the way it was structured, including its instruments and their implementation, as well as the constraints of the LP framework itself. Accordingly, we also suggest the next steps to address the limitations.

It could be argued that the LP patterns that emerged were due to the way the instructor had set up the classroom. From a sociocultural perspective, however, teachers do not have a "causal" relationship but instead a "relationship of influence" with students (Johnson, 2006, p. 245). This means that teachers create conditions for learning but students themselves must transform the conditions into their own actions and abilities. From this perspective also, although the study's findings did not enable us to arrive at a definitive conclusion as to the place of LP in the CoI framework (and nor were they intended to do so), we argue that our findings suggested that LP, and in particular, the aspect of learner agency, was an essential mediating factor in transforming learning in the online classroom studied. Learners clearly took charge of transforming their learning and understanding, not as an isolated action, but rather in tandem 
with their own capacities, interactions with others, and the resources available to them (Lantolf \& Thorne, 2006). Thus, rather than justifying LP's place in CoI, we suggest that the next steps for research should be tracing, describing, and enhancing these learning transformations.

The differences between the findings from the classroom-based discussions and from the survey, require deliberation (see Tables 2 and 3). These differences could perhaps be explained by the survey questions, which might not have achieved full equivalency with Shea et al.'s (2014) indicators. Also, the differences suggested the presence of Schön's (1983) distinction of reflections-on-action from reflections-in-action. In the former, reports are evaluations of completed action, and in the latter, they are descriptions of actions as they are happening. Thus, in completing the survey, the LLTs in the program, for example, looked back at their engagement in completed coursework. In doing so, "Noting Outcomes" in Strategy Use and "Identification of Knowledge Gaps" were more salient in the survey data as they were involved conclusive judgments. The classroom-based findings, in contrast, reflected the latter (reflectionsin-action) and were descriptions of ongoing and day-to-day engagements in the classroom as the LLTs were engaging in them ("Seeking or Offering Information" and "Seeking or Offering Help"). Finally, the discrepancies between the two sets of findings could also be due to the particularities of the different courses taken by the students who were surveyed and the LLTs in the study. Their respective encounters with different content, instructor teaching styles, and length of online exposure, might have led to differences in the responses.

In both the survey and the classroom-based discussion findings, there were few instances of indicators in the logistical categories of Fore-Planning and Goal Setting identified in the course discussion and the survey (see Tables 2 and 3). This was because the researchers focused on data during weeks in which there were no projects or assignments for the class to complete collaboratively, which would have required planning and coordination. Perhaps, however, the findings were also suggesting the limited applicability of Shea et al.'s (2014) framework to describe LP patterns in open-ended discussions beyond those in task-oriented online engagements.

In a similar vein, the Reflection category in Shea et al's framework was limited by two indicators of "Change of Thinking" and "Causal Attribution." As we reported in the findings, using the categories, we were only able to code $4.15 \%$ of classroom discussion data and $3.85 \%$ of the survey responses in the category). The indicators were not able to capture the multiple types of reflections we saw in the data. For example, we had to rely on Du Bois's (2004) framework to notice stance-taking reflections in Donovan's example below:

In my view, we natives are good at "doing" English more than really understanding the underlying framework, and the experience of learning an L2 is completely different (unless you're raised bilingual). In my view, the L2 experience has far more parallels with classroom learning than natives learning at home as soon as they are born. (Second Quarter, 2019-2020 Academic Year).

We hope to show through our subsequent research, other reflective aspects in online engagements. The incorporation of other elements from existing frameworks into the Reflection category could also enrich the category. Given the importance of reflective teaching in teacher learning and Garrison's (2003) reminder that asynchronous online engagement is akin to deliberative reflections, future LP research could focus on online engagements, supported by a more expanded Reflection category. 


\section{Declarations}

The author(s) declare that there is no conflict of interest in this study.

The authors received approval from the ethics review board of Indiana University, USA for this study.

The author received no financial support for the research, authorship, and/or publication of this article. 


\section{References}

Bamforth, E. (2021, April 29). Online college enrollment growth outpaces real-world institutions. EdScoop. https://edscoop.com/online-institutions-enrollment-outpaces-real-worldcollege-thanks-part-time-students/

Bandura, A. (1986). Social foundations of thought and action: A social cognitive theory. Englewood Cliffs.

Batardière, M. T. (2015). Promoting critical thinking in online intercultural communication. The EUROCALL Review, 23(1), 3-10. https://doi.org/10.4995/eurocall.2015.4562

Bauer, M. (2000). Classical content analysis: A review. In M. Bauer \& G. Gaskell (Eds.), Qualitative researching with text, image and sound (pp. 131-151). Sage Publications. https://doi.org/10.4135/9781849209731.n8

Blaine, A. M. (2019). Interaction and presence in the virtual classroom: An analysis of the perceptions of students and teachers in online and blended Advanced Placement classes. Computers \& Education, 132, 31-43.

Candy, L. (2019). The creative reflective practitioner: Research through making and practice. Routledge. https://doi.org/10.4324/9781315208060

Cho, M. H., Kim, Y., \& Choi, D. (2017). The effect of self-regulated learning on college students' perceptions of community of inquiry and affective outcomes in online learning. The Internet and Higher Education, 34, 10-17. https://doi.org/10.1016/j.iheduc.2017.04.001

Crandall, J. (1993). Professionalism and professionalization of adult ESL literacy. Tesol Quarterly, 27(3), 497-515. https://doi.org/10.2307/3587479

Darling-Hammond, L., Hyler, M. E. \& Gardner, M. (2017). Effective teacher professional development. Learning Policy Institute Research Brief.

https://learningpolicyinstitute.org/sites/default/files/productfiles/Effective_Teacher_Professional_Development_BRIEF.pdf

Du Bois, J. W. (2007). The stance triangle. In R. Englebretson (Ed.), Stancetaking in discourse: Subjectivity, evaluation, interaction (pp. 139-182). John Benjamins Publishing Co. https://doi.org/10.1075/pbns.164.07du

Elverici, S. E., \& Karadeniz, Ş. (2018). The effects of social media on social presence in teaching a foreign language. The Journal of International Lingual Social and Educational Sciences, 4(2), 174-185. https://doi.org/10.34137/jilses.432263

Flores-Scott, E. M., \& Nerad, M. (2012). Peers in doctoral education: Unrecognized learning partners. New Directions for Higher Education, 157, 73-89. https://doi.org/10.1002/he.20007 
Fornara, F., \& Lomicka, L. (2019). Using visual social media in language learning to investigate the role of social presence. Calico Journal, 36(3), 184-203. https://doi.org/10.1558/cj.37205

Garrison, D. R., Anderson, T., \& Archer, W. (2001). Critical thinking, cognitive presence, and computer conferencing in distance education. American Journal of Distance Education, 15(1), 7-23. https://doi.org/10.1080/08923640109527071

Garrison, D. R. (2003). Cognitive presence for effective asynchronous online learning: The role of reflective inquiry, self-direction and metacognition. Elements of Quality Online Education: Practice and Direction, 4(1), 47-58.

Garrison, D. R., \& Akyol, Z. (2015). Toward the development of a metacognition construct for communities of inquiry. The Internet and Higher Education, 24, 66-71. https://doi.org/10.1016/j.iheduc.2014.10.001

González Miy, D., \& Herrera Díaz, L. E. (2015). Tracking the path of communities of inquiry in TEFL: A literature review. HOW Journal, 22(1), 80-94. http://dx.doi.org/10.19183/how.22.1.83

Gunter, G. A., Braga, J. D. C. F. B. F., \& Reeves, J. L. (2019). Examining social, cognitive and teaching presences in an online teacher development course using WhatsApp and community of inquiry. FDLA Journal, 4(1).

Hechinger, J., \& Lorin, J. (2020, March 19). Coronavirus forces $\$ 600$ billion higher education industry online. Bloomberg Businessweek. https://www.bloomberg.com/news/articles/2020-0319/colleges-are-going-online-because-of-the-coronavirus

Hedlund, G. (1986). The hypermodern MNC-A heterarchy? Human Resource Management, 25, 9-35. https://doi.org/10.1002/hrm.3930250103

Henri F., \& Rigault C. R. (1996) Collaborative distance learning and computer conferencing. In T. T. Liao (Eds.), Advanced Educational Technology: Research Issues and Future Potential. NATO ASI Series (Series F: Computer and Systems Sciences), vol 145. Springer. https://doi.org/10.1007/978-3-642-60968-8_3

Johnson, K. E. (2006). The sociocultural turn and its challenges for L2 teacher education. TESOL Quarterly, 40 (1), 235-257. https://doi.org/10.2307/40264518

Kang, M., Liew, B. T., Kim, J., \& Park, Y. (2014). Learning presence as a predictor of achievement and satisfaction in online learning environments. International Journal on ELearning, 13(2), 193-208.

Konstantinidis, A., \& Goria, C. (2016). Cultivating a community of learners in a distance learning postgraduate course for language professionals. In S. Papadima-Sophocleous, L. Bradley \& S. Thouësny (Eds.), CALL communities and culture-short papers from EUROCALL (pp. 230-236). Research-publishing.net. https://doi.org/10.14705/rpnet.2016.eurocall2016.567 
Kurek, M., \& Müller-Hartmann, A. (2019). The formative role of teaching presence in blended virtual exchange. Language Learning \& Technology, 23(3), 52-73.

http://hdl.handle.net/10125/44696

Lantolf, J. P., \& Thorne, S. L. (2006). Sociocultural theory and the genesis of second language development. Oxford.

Ma, Z., Wang, J., Wang, Q., Kong, L., Wu, Y., \& Yang, H. (2017). Verifying causal relationships among the presences of the Community of Inquiry framework in the Chinese context. The International Review of Research in Open and Distributed Learning, 18(6). https://doi.org/10.19173/irrodl.v18i6.3197

Milligan, C., Littlejohn, A., \& Margaryan, A. (2014). Workplace learning in informal networks. Journal of Interactive Media in Education, 1(6). http://oro.open.ac.uk/42257/1/325-2585-1PB.pdf

Mokko, M., \& Pawan, F. (2021). Working toward a reconceptualization of effective TESOL teachers' professional development through "Personal Learning Networks." Journal of Global Literacies, Technologies, and Emerging Pedagogies, VII, (1), 1335-1349.

Nami, F., Marandi, S. S., \& Sotoudehnama, E. (2018). Interaction in a discussion list: An exploration of cognitive, social, and teaching presence in teachers' online collaborations. ReCALL: the Journal of EUROCALL, 30(3), 375-398. https://doi.org/10.1017/S0958344017000349

Oleson, A., \& Hora, M. T. (2014). Teaching the way they were taught? Revisiting the sources of teaching knowledge and the role of prior experience in shaping faculty teaching practices. Higher Education, 68(1), 29-45. https://doi.org/10.1007/s10734-013-9678-9

Omohundro, A. (2019). A teacher's perceptions of language learning and social presence in a blended learning community college ESL course (Publication No. 27663900) [Doctoral dissertation, George Mason University]. ProQuest Dissertations Publishing.

Ozbek, C., Comoglu, I., \& Baran, B. (2017). Turkish foreign language learners' roles and outputs: Introducing an innovation and role-playing in Second Life. Contemporary Educational Technology, 8(3), 280-302. https://doi.org/10.30935/cedtech/6201

Ponton, M. K., \& Rhea, E. R. (2006). Autonomous learning from a social cognitive perspective. New Horizons in Adult Education \& Human Resource Development, 20 (2), 38-49. https://doi.org/10.1002/nha3.10250

Pool, J., \& Reitsma, G. (2017). Revised Community of Inquiry framework: Examining learning presence in a blended ode of delivery. Online Learning, 21(3) (2017), 153-165 https://doi.org/10.24059/olj.v21i3.866 
Popescu, E., \& Badea, G. (2020). Exploring a community of inquiry supported by a social media-based learning environment. Educational Technology \& Society, 23 (2), 61-76.

Richardson, S., \& Díaz Maggioli, G. (2018). Effective professional development: Principles and best practice. Cambridge University Press. https://www.cambridge.org/elt/blog/wpcontent/uploads/2018/04/Whitepaper_TD_72dpi-FINAL-ONLINE-VERSION.pdf

Rodriguez, M. E. (2016). Effective pedagogical practices in online English language teacher education (Publication No. 10111587) [Doctoral dissertation, The University of Arizona]. ProQuest Dissertations Publishing.

Rubio, F., Thomas, J. M., \& Li, Q. (2018). The role of teaching presence and student participation in Spanish blended courses. Computer Assisted Language Learning, 31(3), 226250. https://doi.org/10.1080/09588221.2017.1372481

Sarieva, I., \& Badrinathan, V. (2016). Asynchronous online language learning: Some considerations. In G. Chamblee \& L. Langub (Eds.), Society for Information Technology \& Teacher Education International Conference (pp. 2322-2329). Association for the Advancement of Computing in Education (AACE).

Schön, D. A. (1983). The reflective practitioner. Basic Books.

Schumann, A. A. (2019). Developing language learning and cultural awareness by sharing "Lived experiences" in technology (Publication No. 27548951) [Doctoral dissertation, New Mexico State University]. ProQuest Dissertations Publishing.

Scott, K. S., Sorokti, K. H., \& Merrell, J. D. (2016). Learning "beyond the classroom" within an enterprise social network system. The Internet and Higher Education, 29, 75-90. https://doi.org/10.1016/j.iheduc.2015.12.005

Shea, P., \& Bidjerano, T. (2010). Learning presence: Towards a theory of self-efficacy, selfregulation, and the development of a communities of inquiry in online and blended learning environments. Computers \& Education, 55(4), 1721-1731.

https://doi.org/10.1016/j.compedu.2010.07.017

Shea, P., \& Bidjerano, T. (2012). Learning presence as a moderator in the community of inquiry model. Computers \& Education, 59(2), 316-326. https://doi.org/10.1016/j.compedu.2012.01.011

Shea, P., Hayes, S., Uzuner-Smith, S., Gozza-Cohen, M., Vickers, J., \& Bidjerano, T. (2014). Reconceptualizing the community of inquiry framework: An exploratory analysis. The Internet and Higher Education, 23 (10), 9-17. https://doi.org/10.1016/j.iheduc.2014.05.002

Shin, J. K. (2016). Building a sustainable community of inquiry through online TESOL professional development. In J. Crandall \& M. Christison (Eds.), Teacher education and professional development in TESOL: Global perspectives (pp. 143-160). Routledge. https://doi.org/10.4324/9781315641263-9 
Smith, B. L. \& MacGregor, J. T. (1992). What is Collaborative Learning? In A. S. Goodsell, M. R. Maher \& V. Tinto (Eds.), Collaborative learning: A sourcebook for higher education, (pp. 1029). National Center on Postsecondary Teaching.

Singer, N. (2021, April 11). Online schools are here to stay, even after the pandemic. The New York Times. https://www.nytimes.com/2021/04/11/technology/remote-learning-onlineschool.html

Sugarman, J., \& Lazarin, M. (2020). Educating English learners during the COVID-19 pandemic: Policy ideas for states and school districts. Migration Policy Institute.

https://www.migrationpolicy.org/sites/default/files/publications/mpi-englishlearners-covid-19final.pdf

Sun, Y., Franklin, T., \& Gao, F. (2017). Learning outside of classroom: Exploring the active part of an informal online English learning community in China. British Journal of Educational Technology, 48(1), 57-70. https://doi.org/10.1111/bjet.12340

Toyoda, E. (2015). Collaborative video blended learning for exercising higher-order thinkingevaluation using community of inquiry framework. International Journal of Social Media and Interactive Learning Environments, 3(2), 126-141.

https://doi.org/10.1504/IJSMILE.2015.070763

Tunceren, L. L. (2017). Community college second language students' perspectives of online learning: A phenomenological case study (Publication No. 10643256) [Doctoral dissertation, University of South Florida]. ProQuest Dissertations Publishing.

U.S. Department of Education (2021, June 9). Education in a pandemic: The disparate impacts of COVID-19 on America's students. https://www2.ed.gov/about/offices/list/ocr/docs/20210608impacts-of-covid19.pdf

Vinson, D. (2020). The rise of distance learning and the online PhD: Is there cause for concern? PUPN Magazine. https://www.pupnmag.com/article/the-rise-of-distance-learning-and-theonline-phd-is-there-cause-for-concern/

Witthaus, G. (2018). Findings from a case study on refugees using MOOCs to (re)enter higher education. Open Praxis, 10(4), 343. https://doi.org/10.5944/openpraxis.10.4.910

Woods, L., Priest, H., \& Roberts, P. (2002). An overview of three different approaches to the interpretation of qualitative data. Part 2: Practical illustrations. Nurse Researcher, 10(1), 43-51. https://doi.org/10.7748/nr2002.10.10.1.43.c5878

Zimmerman, B. (2011). Motivational sources and outcomes of self-regulated learning and performance. In B. J. Zimmerman \& D. H. Schunk (Eds.), Handbook of self-regulation of learning and performance (pp. 49-64). Routledge. 


\section{Appendix A}

\section{Survey \#1 Patterns of Online Engagement Survey}

\section{[Questions based on Shea et al. (2014)]}

1. Do you set goals beforehand in online discussions?

2. Do you plan on specific methods or strategies to use to discuss?

3. Do you coordinate (delegate, assign, distribute, sequence, etc.) tasks for yourself and/or for others in the discussions?

4. Do you check or verify your understanding (e.g., of readings/postings etc.) during discussions?

5. Do you identify problems or issues (e.g., in the readings/postings etc.) during discussions?

6. Do you indicate/note when certain tasks/activities/goals have been accomplished?

7. Do you evaluate the quality of your contributions to the discussion?

8. Do you evaluate the quality of your classmates' contributions to the discussion?

9. Do you monitor the discussions AND suggest/make corrections based on feedback and reflections?

10. Do you appraise/comment on your own engagement, interest, commitment, and participation?

11. Do you appraise/comment on classmates' engagement, interest, commitment, and participation?

12. During the discussions, do you appraise/comment on your reactions to tasks or materials used?

13. During the discussions, do you appraise/comment on classmates' reactions to tasks or materials used?

14. Do you recognize and acknowledge your own strengths, weaknesses \& preferences in learning \& engaging?

15. Do you recognize and acknowledge other peoples' strengths, weaknesses \& preferences in learning \& engaging?

16. Do you advocate or encourage others to contribute \& participate?

17. Are you aware of the methods or strategies you use in discussions?

18. Do you offer help to others during online discussions?

19. Do you seek help during online discussions?

20. Do you become aware of knowledge gaps you might have (e.g. to complete a task/to understand readings) during online discussions? 
21. Do you see the need to or engage in a review of course materials/content during online discussions?

22. Are you able to make connections between discussions to a future outcome (in your studies, research, work, training, etc.)?

23. Do you seek additional information (e.g., new material, personal experiences) beyond the course content $\&$ materials to deepen understanding?

24. Do you offer additional information (e.g., new material, personal experiences, etc.) beyond the course content \& materials to deepen understanding?

25. Do the online discussions result in a change in your thinking?

26. Do the discussions impact how you plan, monitor, or use strategies in online discussions?

27. Do you see the discussions impacting how your classmates plan, monitor, or use strategies in online discussions?

\section{Appendix B}

\section{Interview Questions}

1. The analysis showed that most of your engagements were seeking and providing information. Discuss this move and how it reflects on what you feel needed to be done in this class and the doctoral program as a whole.

2. The analysis also showed that you were monitoring and appraising your own and the engagement of others. Discuss this move and how it reflects on what you feel needed to be done in this class and the doctoral program as a whole. 